EESTI NSY TEADUŚTE AKADEEMIA TOIMEETISEDE. V KÖIDEE

BIOLOOGILINE SEERIA 1956, NR. 3

ИЗВЕСТИЯ АКАДЕМИИ НАУК ЭСТОНСКОЙ ССР. ТОМ V

СЕРИЯ БНОЛОГИЧЕСКАЯ. 1956, № 3

\title{
JUUREPESSU (FOMITOPSIS ANNOSA) BIOLOOGIAST
}

\author{
E. PARMASTO, \\ bioloogiateaduste kandidaat
}

Juurepessu (Fomitopsis annosa (Fr.) Karst., sünonüümid: Fomes annosus (Fr.) Cke., Trametes radiciperda Hart.) peetakse õigusega Eesti NSV üheks levinumaks ja kahjulikumaks puumädanike tekitajaks (Karu, 1939, 1953). Kuna see seen põhjustab ulatuslikke kahjustusi peaaegu kogu Euroopas, on ta olnud metsateadlaste ja mükoloogide pideva huvi objektiks. Sellest hoolimata on juurepessu tõrjeviisid veel üsna puudulikud ning seene bioloogiat tuntakse halviasti.

Juurepess esineb Eesti NSV-s kasvavail kuuskedel, siberi ja palsamnulul*, harvem ka mändidel ning ainult üsna juhuslikult lehisel, kadakal ja arukasel, tekitades tüve alumise osa ja juurte kirjut korrosioonmädanikku. Teistes maades kahjustab juurepess paljusid okaspuid, üksikjuhtudel ka lehtpuid; mõnikord on teda leitud isegi kanarbikul, mustikal ja kukemarjal.

Erinevalt paljudest teistest torikuliste hulka kuuluvatest seentest-metsakahjuritest võib juurepess levida haigestunud puudelt ligiduses asetsevatele juurte kokkupuutekohtade kaudu ning mütseeli edasitungimise teel mullas. Peamine metsapat oloogide tähelepanu ongi pöönatud sellisele, metsamajanduse praktikas kahtlemata väga olulisele levimisviisile (Анкудинов, 1951; Ванин, 1955; Руководящие указания, 1953). Seevastu juurepessu leviku vastu eostega pole tuntud peaaegu mingit huvi, kuigi just ainult selliselt saab toimuda uute puistute nakatumine ning seene levik suurematesse kaugustesse.

Vanemas, osalt aga ka uuemas kirjanduses levinud andmetel tekivad juurepessu viljakehad kahjustatud puude külgjuurtel või nende all, ning ainult üsna harva vanadel kändudel või lamapuidul (Гартиг, 1894; Karu, 1939; Ванин, 1955; Власов, Воронцов и др., 1955). Asjaolust, et viljakehad arenevad peamiselt maa-alustel juurtel, tegi Hartig (Гартиг, 1894) järelduse, et hiired ning teised urgudes elutsevad loomad kannavad oma karvades edasi juurepessu eoseid. See julge oletus koos väitega, et viljakehad kasviavad peamiselt maa all, on väga levinud metsanduse praktikute hulgas ning on leidnud tee ka paljudesse käsiraamatutesse (Hiley, 1919; Daniel, 1935; Бондарцев, 1953; Ванин, 1955 jt.).

\footnotetext{
* A. Karu teateil.
} 
Tegelikult kasvavad jum

aegu eranditult kändudel ja lassu viljakehad Eesti NSV tingimustes peajärelevaatus näitas, et viljakehapuidul. Suure hulga tuuleheidetud kuuskede nende allkülgedel, nad on aga võivad esineda küll puu juurtel ja isegi p är a s t tuuleheidet, mitte enne _- väheste eranditega - ikka tekkinud silmas, et torikuliste hümenofoor tega; võib oletada, et viimast asjaolu plati vertikaalselt asetunud torukesAnkudinov (Анкудинов, 1951) väidab, et jua uurijad alati arvestanud. Ka surnud juurtel varjurikastes kohtades. et juurepessu viljakehad arenevad kohtades (juurte vahel jne.) Kõ̃i Viljakehade esinemine varjulistes Eesti NSV-s.

Viljakehade ilmumise aja kohta leidub mofal'i (Самофал, 1926) andmeil tekiva kirjanduses ainult üks märge: Sapessu sporulatsiooni (eoste-eraldumivad nad alates juuli keskpaigast. Juurenekaer (1938). Taanis aastail 1930 vaatlused näitasid, et sporulatsioon -1933 7 eksemplari juures läbiviidud lõpuni ning jätkus pärast umbes kuu toimus aprillist juulini või augusti isegi maini. Tuleb aga silmas pidada Eesti NSV omadest tublisti erinevad: jet Taani klimaatilised tingimused on seal 0 kuni $+1^{\circ} \mathrm{C}$. duses üldse väga vähe arenemise ja sporulatsiooni kohta leidub kirjan25 liiki; enamus vaatlusi on teostatudes suhtes on käsitlust leidnud ainult sedagi sageli laboratoorsetes tingimusterne üksiku eksemplari juures ning nimustes, kus saadi moonutatud pilt tege-

Sporulatsiooni ulatusli

puudulikkus. Kasutatavamad uurimist on takistanud vastava metoodika hümenofoori alla asetatud paberilehedid põhinevad nähtusel, et viljakeha tamata silmaga vối mikroskoobi abil lähgedes moodustavad eosed varus1920; Riley, 1925) on paberilehe asemel kirme. Mõned autorid (White, asemel kasutanud ka mikroskoobi-alus-

Eeoste kogunemist paberilehele või alusklaasile takistc (eriti tuul), mis kannavad enamiku vabanenuasile takistavad õhuvoolud dumiseks ümbritsesid mõned uurijad vaadeld eostest eemale. Sellest hoi(Percival, 1933) või esiküljel klaasiga varustatud viljakehad plekknõuga 1940). Sellise abinõu puudusteks on aga viljatatud puukastiga (Борисов, erinevatesse temperatuuri ja õhuniiskuse tingehade asetamine looduslikust meetodi tülikus ja kulukus, mis võimuse tingimustesse, veelgi enam aga tud arvu eksemplaride juures.

Bjørnekaer (1938) kasutas eoste

(kapsleid). Kapslikese põhja asetati püüdmiseks õllepudelite metallkorke külgejoodetud plekiribakese abil väikese meetodi puuduseks tuleb lugeda viljake naelaga viljakeha allküljele. Selle autori vaatluste järgi põhjustab metallesema pidevat vigastamist naelaga; päeva jooksul vastava hümenofoori osa surema kokkupuutumine juba mône külgejoodetud plekiga küllalt ruttu roostetavase. Kuna metallkapslid koos hulgal, mis samuti on ebamugav.

Torikuliste sporulatsiooni

res teostas autor Eesti Põlluma jälgimiseks suurema arvu eksemplaride juumajandis kahe aasta vältel statsiduse Akadeemia Järvselja õppe- ja katsetud ja muudetud kujul Bjørnekaeri meetodit. vaatlusi, kasutades parandapandi tumedast läikpaberist kettake; kapsel Limonaadipudeli kapsli põhja üve või muu substraadi külge kinnitatud pla asetati elastse, naeltega puuapsli ülemise serva ja hümenofoori pinna vahela abil viljakeha alla, jättes una kapslike lebas vabalt plekiribá nõgusal $1-2 \mathrm{~mm}$ ruumi (joon. 1).

4 ENSV Tead. Akad. Toimetised; b'ol. s. 3 
kiire vahetamine uuega vaatluste teostamise ajal mingeid raskusi. Viljakehast vabanenud eosed, langedes tumedale läikpaberile, moodustavad isegi väga väikeste koguste puhul varustamata silmaga nähtava kirme. Vaatlusi teostati ühe- või kahenädalaste ajavahemike järel 1953. ja 1954. a. kogu vegetatsiooniperioodi jooksul; piiratud ajavahemikus teostati ka igapäevaseid vaatlusi. Eraldunud eoste hulk märgiti kui puuduv, vähene, keskmine või rohke; see võimaldas hinnata ühe ja sama viljakeha sporulatsiooni suh-

telist intensiivsust eri

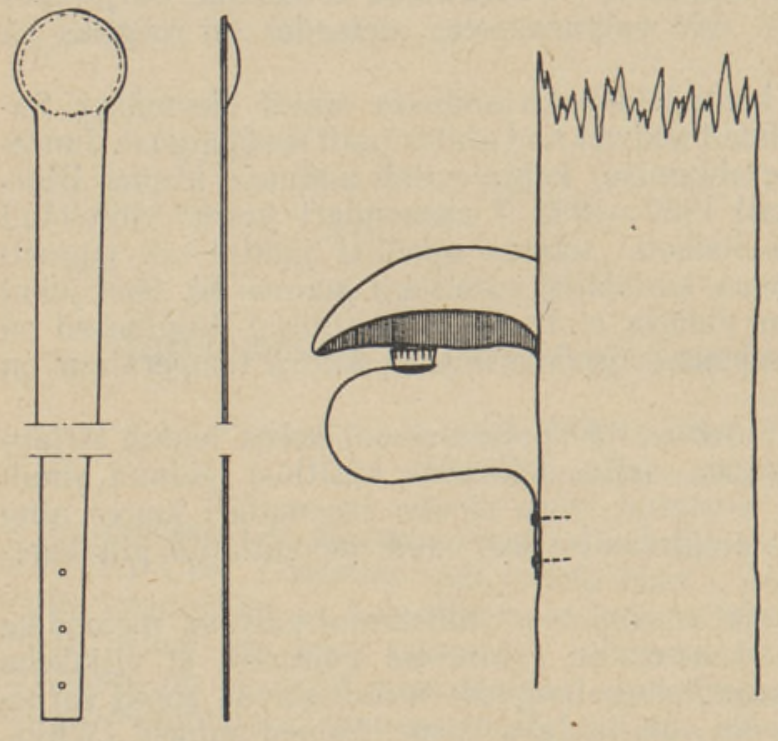

Joon. 1. Eostepüüdja ehituse ja paigutamise skeem. aegadel. Rööbiti teostati ka vaatluskoha mikrokliima jälgimist termograafi ja hügrograafi abil.

Kokku teostati vaatlusi 9 juurepessu eksemplari juures, neist 4 juures 2 aasta vältel (joon. 2). Vaatlusalaks oli jänesekapsa-kuusik, kus viljakehad kasvasid kuusekändude juurtel ja lamavatel tüvedel.

Uued juurepessu viljakehad ilmusid suve keskel - juulis ja augustis. Peaaegu samal ajal - juuni keskpaigast juulini või isegi alles augustis algas vanematel viljakehadel uue hümenofoori osa (torukestekihi) tekkimine. Umbes nädal või paar pärast seda algas sporulatsioon, mis kestis märgatavate vaheaegadeta novembri teise pooleni või isegi detsembri alguseni (1953. a.). Torukestekihi paksenemine - s. t. hümenofoori kasv toimus aeglaselt ning jõudis lôpule alles septembris.

Pärast talvist vaheaega algas sporulatsioon uuesti aprillis või harvem mai algul ning kestis juunini (üksikjuhtudel ainult maini); siis algas eespool juba kirjeldatud nädalane vôi paarine vaheaeg, millal toimus uue hümenofoori teke. Tuleb märkida, et hümeenium (basiidiumid) hävib talveks ja tekib kevadel uuesti, mingit muud kasvu aga kevadel ei toimu. Nii kestab juurepessu (nagu rea teistegi torikuliste) viljakehade «vegetatsiooniperiood» suvest suveni, erinedes sellega enamikust teistest seentest ning taimedest. Tuleb märkida, et seene kasvamise ja intensiivse sporulatsiooni ajal esineb sageli gutatsioon, seejuures isegi üsna madalate temperatuuride juures $\left(0-5^{\circ} \mathrm{C}\right)$.

Sporulatsiooni kestus aastas on eri eksemplaridel erinev ning kõigub 4 ja 7 kuu vahel (enamasti 6-7 kuud). Suvine kõrge õhutemperatuur Eesti NSV tingimustes sporulatsiooni nähtavasti ei takista. Eoste eraldumine toimub ka küllalt madala temperatuuri puhul; näiteks leidis see aset kõigi eksemplaride juures 11. XI 1954 (ōhu keskmine $t^{\circ} 1,9^{\circ}$, maksimaalne $3,2^{\circ}$, minimaalne $\left.-0,2^{\circ} \mathrm{C}\right)$. 1954 . a. mai keskel esinenud temperatuuri langus ning kuni $-2,5^{\circ} \mathrm{C}$ ulatunud öökülmad ei katkestanud sporulatsiooni ühekski päevaks, kuigi vähendasid selle intensiivsust.*

* Erandiks on eks. nr. 111, mis ei sporuleerinud 15. V 1954. 


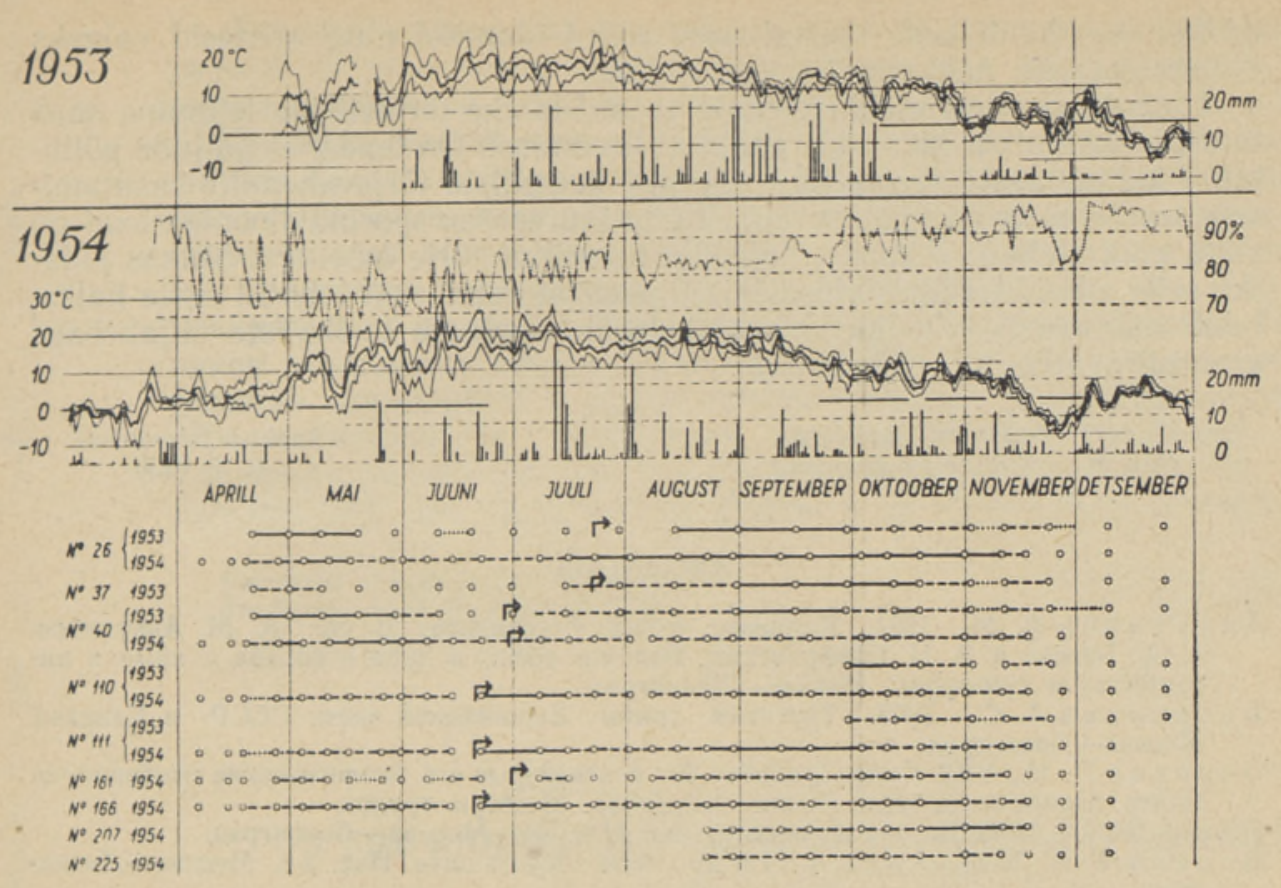

Joon. 2. Juurepessu viljakehade areng ja sporulatsioon. Olal on märgitud päevade maksimaalsed, keskmised ja minimaalsed temperatuurid ning sademete hulk, 1954. aasta kohta ka ōhu relatiivne niiskus.

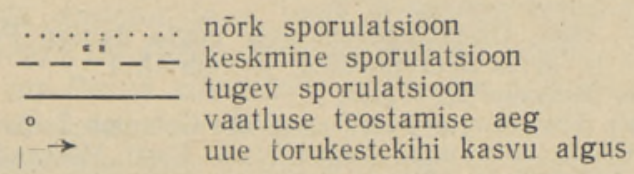

Sporulatsiooni sõltuvus õhu niiskussisaldusest selgus 15 . VII kuni 16. VIII 1954 teostatud igapäevastest vaatlustest. Enamikul vaatluseksemplaridest toimus 18 . VII ja 26.-28. VII märgatav sporulatsiooni tugevnemine; see langes ühte õhuniiskuse suurenemisega nendel päevadel enam kui $10 \%$ võrra. Vlaheaeg sporulatsioonis esines vaatluseksemplari nr. 40 juures 31. VII-7. VIII, nr. 161 juures 17 . VII-23. VII ja 28. VII-7. VIII; enamiku eksemplaride juures esines sporulatsiooni nõrgenemine 18., 20. ja 26. VII. Ulalmärgitud kuupäevadel esines õhuniiskuse vähenemist või selle madalat taset. Nende andmete alusel võib väita, et sporulatsiooni esinemine ja intensiivsus sõltuvad õhu relatiivsest niiskusest ning suurenevad viimase tõustes.

Eoseid eraldus enamasti suhteliselt rohkesti; suvel eraldasid viljakehad soodsate ilmade puhul juba mõne tunni jooksul hästimärgatava valge kihi eoseid. Tuleb märkida, et kuigi enamik viljakehasid asus ainult $5-20 \mathrm{~cm}$ kõrgusel maapinnast ning tuulevarjulistes kohtades, ei kogunenud viljakeha alla kunagi märkimisväärset eostekirmet. Nähtavasti piisab isegi niisugusest väikesest kơrgusest selleks, et õhu liikumised suudavad rõhuva enamiku eostest endaga kaasa viia. Ka see vaatlus on vastuolus Hartigi eespooltoodud väitega juurepessu eoste leviku kohta loomade abil.

Uksikutel juhtudel, kui viljakeha alumine pind asus ainult mõne sentimeetri kõrgusel maapinnast, võis märgata eostekirme tekkimist maapinnal. 
Küllaldase õhuniiskuse puhul need eosed idanesid ning arenesid valgeks mütseeliks, mis nähtavasti toitus mullast.

Uute ja senisest efektiivsemate puumädanike tõrjeviiside leidmine saab toimuda torikuliste bioloogia paremal tundmisel. On teada, et paljude põllu. taimi kahjustavate seente tõrje tugineb keemiliste tõrjevahendite kasutamisele seente eoste-eraldumise lajal. Kuna juurepessu sporulatsiooniperiood on väga pikk (6 kuni 7 kuud), pole siin keemiline tõrje mõeldav. Silmas pidades selle aja vältel ühestainsastki viljakehast vabanevat tohutut eoste hulka, tuleb nähtavasti tulevikuski peatähelepanu pöörata torikuliste viljakehade arvu piiravatele tõrjevahenditele.

Eesti NSV Teaduste Akadeemia

Zooloogia ja Botaanika Instituut
Saabus toimetusse

6. I 1956

\title{
KIRJANDUS
}

Анкудин о в А. М., 1951. Корневая губка в сосняках. В сб.: А. М. Анкудинов. А. А. Власов и В. Н. Шафранская, Болезни сосны и дуба и борьба с ними в питомниках и культурах. Москва-Ленинград.

Бонд а рцев А. С., 1953. Трутовые грибы Европейской части СССР и Кавказа. Москва-Ленинград.

Б о р и с о в П. Н., 1940. Fomes igniarius Fr. и некоторые его биологические особенности. Центр. научно-иссл. инст. лесного хозяйства, 15 сборн. трудов.

В а н и н С. И., 1955. Лесная фитопатология. Изд. 4-е. Москва-Ленинград.

В л а с о в А. Ӓ., В ор о ц о В А. И и др., 1953. Лесозашита. Изд. 2-е. Москва-Ленинград.

Г а р ти г Р., 1894. Болезни деревьев. Москва.

Руководящие указания по лесозащите, 1953. Часть I. Москва-Ленинград.

С а м о фал С. А., 1926. Паразитные грибы - Armillaria mellea Quélet и Polyporus annosus Fries в сосновых борах и их значение в лесокультурном деле. Материалы по микологии и фитопатологии $\mathrm{V}, 2$.

B jørneka er, K., 1938. Undersøgelser over nogle danske Poresvampes Biologi med saerligt Hensyn til deres Sporefaelding. Friesia II, 1.

D a n i e 1, O., 1935. Metsakaitse. Tartu.

Hi ley, W. E., 1919. The Fungal Diseases of the Common Larch. Oxford.

K a r u, A., 1939. Mönda okaspuude punamädast. Eesti Metsanduse Aastaraamat IX.

$\mathrm{K}$ a r u, A., 1953. Juurepessu (Fomes annosus) kahjustuse olenevus mullastiku tingimustest Eesti NSV kuusepuistutes. Loodusuurijate Seltsi juubelikoguteos.

Perciva 1, W. C., 1933. A Contribution to the Biology of Fomes pini (Thore) Lloyd. New York State Coll. Forestry, Tech. Publ., 40.

R i ley, C. G., 1952. Studies in Forest Pathology IX. Fomes igniarius decay of Poplar. Canadian Jour. Botany, 30, 6 .

Whit e, J. H., 1920. On the Biology of Fomes applanatus (Pers.) Wallr. Transact. Royal Canadian Institute XII, 2. No. 28.

\section{О БИОЛОГИИ КОРНЕВОЙ ГУБКИ (FOMITOPSIS ANNOSA)}

\author{
Э. Х. ПАРМАСТО, \\ кандидат биологических наук
}

Резюме

Корневая губка (Fomitopsis annosa (Fr.) Karst.) встречается в Эстонской ССР преимущественно на ели и на сибирской и бальзамической пихтах, меньше на сосне и только случайно на лиственнице, можжевельнике и березе бородавчатой. Плодовые тела гриба можно найти на пнях и валежных стволах, а на корнях живых деревьев - только как редкое исключение. 
Для наблюдения над выделением спор был применен усовершенствованный автором метод Бьёрнекера (Bjørnekaer, 1938) (рис. 1). Плодовые тела корневой губки появляются в Әстонской ССР в июле и августе. Споруляция совершается с июля или августа по вторую половину ноября или начало декабря и с апреля (реже с начала мая) по июнь. Затем следует перерыв, длящийся одну или несколько недель; в это время начинается рост нового слоя трубочек (рис. 2). Споруляция наблюдается как при теплой погоде, так и при низких температурах $\left(2-3^{\circ} \mathrm{C}\right)$ и не прекращается даже под влиянием коротких ночных заморозков. Под влиянием повышения относительной влажности воздуха интенсивность споруляции повышается, а при понижении может временно прекратиться. Продолжительность споруляции составляет (4) $-6-7$ мес. в год. Главными распространителями спор являются, повидимому, не подземные грызуны, как предполагали Гартиг и др., а воздушные течения.

Институт зоологии и ботаники Академии наук Эстонской ССР

Поступила в редакцию 6 I 1956

\section{ON THE BIOLOGY OF FOMITOPSIS ANNOSA (FR.) KARST.}

\section{E. PARMASTO}

\section{Summary}

Fomitopsis annosa is a very common species in the Estonian SSR, where it appears on Picea excelsa, Abies sibirica and A. balsamea. It occurs more rarely on Pinus silvestris, and only occasionally on Larix, Juniperus communis and Betula verrucosa. The fruit-bodies grow on stumps and logs; only very rarely are they found lattached to the roots of living trees.

Fruit-bodies of this species appear in Estonia from July to August. Observations of sporulation were carried out by means of the improved method of Bjørnekaer (fig. 1). Sporulation lasts from July or August to the end of November and from April (rarely from the beginning of May) to June. When the new tube-layer is beginning to form, there is an interval of one or several weeks in the sporulation (in June or July) (fig. 2). Sporulation also takes place at lower temperatures (from $2^{\circ}$ to $3^{\circ} \mathrm{C}$ ) and is not stopped even by short night frosts. Sporulation is stimulated by an increase in the relative humidity of the air, and may be weakened or halted by a decrease in humidity. Sporulation lasts from six (rarely from four) to seven months in the year. The principal factors in the distribution of spores are applarently air currents, and not underground rodents, las has been supposed by Hartig and others.

Academy of Sciences of the Estonian SSR, Institute of Zoology and Botany

Received Jan. 6,1956 